\title{
철스크랩의 리사이클링
}

\author{
§손호상 \\ 경북대학교 신소재공학부

\section{Recycling of Ferrous Scraps}

\author{
${ }^{\S}$ Ho-Sang Sohn \\ School of Materials Science and Engineering, Kyungpook National University, Daegu 41566, Korea
}

\section{요 약}

본 논문에서는 철강제조 프로세스, 철스크랩의 전처리와 미량 원소, 그리고 철강공정에서 발생하는 분진의 리사이클링 기술에 대해 고찰하였다. 철강은 인류가 가장 많이 사용하는 범용 금속으로, 2018 년 기준 전세계 조강 생산량은 18 억 톤을 초과하였다. 철을 리사이클 링하면 철광석으로부터 환원하여 철강재를 얻는 것에 비하여 $\mathrm{CO}_{2}$ 발생량은 약 $42 \%$ 수준이며, 에너지는 약 $60 \%$ 를 절약할 수 있다. 철스 크랩은 스크랩을 주원료 사용하는 전기로제강과 철광석을 주원료로 사용하는 전로 제강공정에서 리사이클링되고 있다. 철스크랩을 주원 료로 사용하는 전기로 제강법은 스크랩을 예열하는 장치를 부가한 에너지 절약형으로 바뀌어 가고 있다. 철강 제조공정에서 발생하는 분 진은 제철소 내에서 다양한 방법으로 리사이클링하여 철분과 아연 등을 회수하고 있다.

주제어 : 철스크랩, 전기로제강, 슈레더, 분진, 미량원소, 철강

\begin{abstract}
This work provides an overview of the steel production process, pretreatment and tramp elements of scraps and recycling technology of dust generated from steelmaking process. Steel is the most common metal used by mankind, with the world production of crude steel in 2018 exceeding 1.8 billion tonnes. Recycling of ferrous scraps reduces $\mathrm{CO}_{2}$ emissions by about $42 \%$ and saves about $60 \%$ of energy, compared to production steel from iron ore. Steel scraps are usually recycled to both an electric arc furnace (EAF), scrap-based steelmaking and the basic oxygen furnace (BOF), in ore-based steelmaking. EAF steelmaking, which uses iron scrap as a main raw material, is changing to an energy-saving type with a device for preheating scrap. Dust generated from the steelmaking process is recycled in various ways in the steel mill to recover iron and zinc.
\end{abstract}

Key words : ferrous scrap, EAF steelmaking, shredder, dust, minor elements, iron \& steel

\section{1. 서 론}

철(鐵, iron, $\mathrm{Fe})$ 은 구조용 금속으로는 알루미늄(Al) 다 음으로 지구상에 가장 많이 존재하는 금속이면서, 인류가
가장 많이 사용하는 금속이다. 철은 차량, 선박, 항공기, 주택, 각종 생활용품에 이르기까지 많은 분야에서 사용되 고 있으므로 철이 없는 세상은 상상하기 힘들 정도로 중요 한 금속이다.

\footnotetext{
- Received : December 23, 2019 · Revised : February 13, $2020 \quad \cdot$ Accepted : February 18, 2020

$\S$ Corresponding Author : Ho-Sang Sohn (E-mail : sohn@knu.ac.kr)

School of Materials Science and Engineering, Kyungpook National University, 80 Daehak-ro, Buk-gu, Daegu 41566, Korea

(c) The Korean Institute of Resources Recycling. All rights reserved. This is an open-access article distributed under the terms of the Creative Commons Attribution Non-Commercial License (http://creativecommons.org/licenses/by-nc/3.0/), which permits unrestricted non-commercial use, distribution and reproduction in any medium, provided the original work is properly cited.
} 
이러한 철강의 기원은 불분명하지만, 소아시아지역에 서 B.C. 2,100 년 경의 철 유적지가 발견되어 약 4,100 년 전부터 철을 사용하여 온 것으로 추정하고 있다. B.C. 3,000 년 경에는 메소포타미아, 이집트 지역까지 철을 정 련하는 기술이 알려졌다. 그러나 철을 실제 생활에 사용 하여 철기시대가 시작된 것은 B.C. 8세기 경이며, 이집트 에서는 B.C. 6세기에 이르러서야 철을 사용하게 되었다 ${ }^{1)}$. 한반도의 철기문화는 한반도 서북 지역에서 중국 한(漢) 나라 시대 이전의 것으로 보이는 주조 철기가 발굴되어 기 원전 3 4세기 무렵부터 독자적인 형태로 발전되어 온 것 으로 추정하고 있다. 이러한 한반도의 철기문화는 가야에 이르러 찬란한 금자탑을 이룬다.

이처럼 오랜 역사를 가지고 있는 고대금속인 철강 재료 는 수집하여 용해하고 성분조정을 거치면 곧바로 재사용 할 수 있으므로 리사이클링하기 쉬운 재료이다. 따라서 그동안 스크랩이 된 철강재의 약 $90 \%$ 이상은 리사이클 링하여 왔다. '삼국사기'의 문무왕(661년 681년) 본기 문 무왕 21년에 수록된 문무왕 유조에 의하면 ‘무기를 녹여 농기구를 만들었고, 백성을 어질고 오래 살게 하였다.'라 는 이야기가 실려 있다. 고려시대에도 성종(981년 997 년) 6 년에 개혁의 일환으로 칼을 녹여 농기구를 만들었다 고 전해 진다 ${ }^{2}$. 비록 이러한 내용은 통치의 수단으로 철을 리사이클링한 것이지만, 옛사람들도 철강재료를 리사이 클링하여 온 것을 의미한다.

한편 우리 생활과 밀접한 부분에서 다양하게 사용되고 있는 철강재료는 다른 금속들과 마찬가지로 수명이 다하 면 리사이클링할 수 있는 매우 환경 친화적인 금속이다. 특히 철스크랩으로부터 철강재를 생산하는 경우 철광석 으로부터 환원하여 철강재를 얻는 것에 비하여 $\mathrm{CO}_{2}$ 발생 량은 약 $42 \%$ 수준이며 ${ }^{3)}$, 에너지는 약 $60 \%$ 를 절약할 수 있다).

2018년의 전세계 조강(crude steel)생산량은 18 억 톤을 초과하였다. 이러한 양은 전체 금속 생산량의 약 $95 \%$ (중 량기준)를 차지한다. 그리고 이 중에서 철스크랩을 주원 료로 사용하는 전기로법에 의한 조강 생산량은 약 $28 \%$ 이지만, 고로법에서도 전로에 일정량의 철스크랩을 투입 하므로 리사이클링률은 이보다 높다. 우리나라의 전체 조 강 생산량은 약 7,246만 톤이며, 이 중에서 약 $33 \%$ 가 전 기로법에 의해 생산되었다 ${ }^{5}$.

본 연구에서는 이러한 철강재의 리사이클링을 이해하
기 위해 철강 제조공정과 철스크랩의 리사이클링 기술 및 철강재 생산과정에서 발생하는 더스트 등의 처리 기술에 대해 고찰하였다.

\section{2. 조강 생산량과 리사이클링}

인류가 1900년부터 생산한 물질 가운데 가장 많이 생 산한 것은 시멘트로서 2010년에만 약 35억 톤을 생산하 였다 ${ }^{6}$. 그 다음으로 대량 생산한 것이 철강이며, 2018년 에는 18 억 톤 이상을 생산하였다. Fig. 1에는 1900년부터 2018년까지의 조강 생산량 변화를 나타내었다. 2차 대전 이 끝나고 경제 재건기인 1950년대에 들어서면서 2억 톤 을 돌파한 후 생산량이 급격하게 증가하였다. 특히 이 시 기에 순산소 전로법(BOF, Basic Oxygen Furnace)이 실 용화되어 철강의 대량 생산에 기여한 것을 알 수 있다. 이 후 80 년대 말까지 8 억 톤 미만을 생산하였으나, 90 년대에 들어와서 중국의 철강특수에 힘입어 전세계 조강 생산량 은 급격하게 증가하기 시작하여 지금에 이르고 있다. 2018 년 현재 중국의 조강 생산량은 약 9.3 억 톤으로 전세계 조 강 생산량의 반 이상을 차지하고 있닥.

한편 전기로(Electric Furnace, EF) 제강법에 의한 조강 생산량은 꾸준히 증가하지만, 전체 조강 생산량의 증가에 따라 90 년대 말까지는 거의 $35 \%$ 수준을 유지하였다. 그 러나 2000년대에 들어서면서 중국의 BOF법 조강 생산량 (조강 생산량의 약 $90 \%$ )의 급격한 증가에 따라 $\mathrm{EF}$ 법의 생산비율은 약 $25 \%$ 수준까지 감소하였으나, 최근에 다 시 증가하는 추세이며, 2017년에는 전체 조강 생산량의 약 $28 \%$ 수준인 약 4.7 억 톤을 $\mathrm{EF}$ 법으로 생산하였다. 그

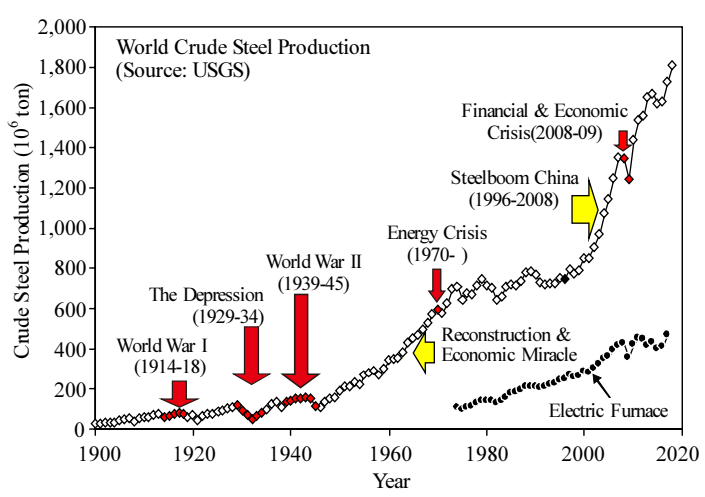

Fig. 1. World production of crude steel (Source: USGS). 
러나 BOF법에서도 조강 생산량의 약 $15 \%$ 정도는 철스 크랩을 사용하므로 실제 철스크랩 사용량은 6 억 톤을 초 과하는 것으로 추산하고 있다.

Fig. 2에는 우리나라의 BOF법과 EF법에 의한 조강 생 산량을 비교하여 나타내었다. $\mathrm{EF}$ 법에 의한 조강 생산량 은 1990년대 초반 약 $35 \%$ 수준에서 꾸준히 증가하여 2000 년대에는 약 $45 \%$ 까지 증가하였다. 그러나 현대제 철이 본격적으로 가동되면서 약 $30 \%$ 수준까지 감소하였 으나, 최근에는 다시 증가하여 2017년 기준 약 $33 \%$ 인 2,300 만 톤 이상을 $\mathrm{EF}$ 법으로 제조하였으며, 나머지인 약 4,770 만 톤을 BOF법으로 제조하였다. BOF법에서도 원 료의 약 $10 \%$ 이상은 철스크랩을 사용하므로 약 2,800 만 톤의 철스크랩을 사용하는 것으로 추정할 수 있다.

Table 1에는 철강재의 용도를 나타내었다 ${ }^{8,9)}$. 전세계 생산량의 약 $50 \%$ 정도는 건설 등의 인프라 구축에 사용 되고 있다. 이러한 경향은 개발도상국일수록 그 비율이 높아지며, 선진국의 경우 약 $30 \%$ 수준인 것으로 알려져 있다. 그 다음으로 기계설비, 자동차 등의 수송기기 제작

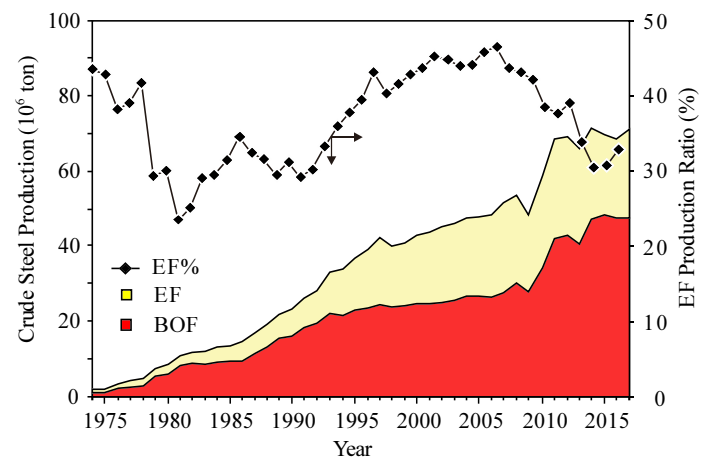

Fig. 2. Crude steel production of Korea and ratio of EF steel production.

Table 1. The use of steel products (\%)

\begin{tabular}{|c|r|r|}
\hline Product & 2011 & 2014 \\
\hline Building \& Infrastructure & 51.2 & 50.0 \\
\hline Mechanical Equipment & 14.5 & 16.0 \\
\hline Automotive & 12.0 & 13.0 \\
\hline Other Transport & 4.8 & 5.0 \\
\hline Metal Products & 12.5 & 11.0 \\
\hline Electrical Equipment & 3.0 & 3.0 \\
\hline Domestic Appliances & 2.0 & 2.0 \\
\hline
\end{tabular}

에 사용되고 있다. 이러한 용도별 사용량의 추세에는 큰 변화가 없을 것으로 생각된다.

Table 2에는 철강재의 용도별 수명과 리사이클링률을 나타내었다 ${ }^{10)}$. 수명은 건축의 경우가 가장 길며, 스틸캔 등이 가장 짧은 것을 알 수 있다. 한편 철강의 리사이클링 률은 비교적 높은 편이지만, 일반 소비재와 스틸캔의 경 우 $50 \%$ 및 $69 \%$ 로 낮은 편이다. 세계철강협회에서는 2050 년까지 기계류는 $95 \%$, 건설 및 수송기기는 $90 \%$ 이 상의 리사이클링률을 목표로 하고 있다. 한편 이러한 내 구년수와 리사이클링률을 고려하면 향후 10 년 이내에 중 국에서 다량의 철스크랩이 발생될 것으로 예상된다.

Fig. 3에는 철의 라이프 사이클을 나타내었다 ${ }^{11)}$. 철강 재의 라이프 사이클은 고로 일관 제철소에서 철광석을 코 크스로 환원하여 선철이 생산되면서 시작된다. 용융선철 은 전로에 투입되어 용강이 만들어지며, 필요한 형상으로 주조한다. 주조한 강재를 각종 제품으로 만들기 위해 가 공하며, 이 과정에서 '가공 스크랩’이 발생한다. 그리고

Table 2. Steel industry recycling rates and life time

\begin{tabular}{|c|c|c|c|}
\hline \multirow{2}{*}{ Product } & \multirow{2}{*}{$\begin{array}{c}\text { Lifetime } \\
\text { (years) }\end{array}$} & \multicolumn{2}{|c|}{ Recycling rate (\%) } \\
\cline { 3 - 4 } & & 2007 & 2050 \\
\hline Construction & $40 \sim 70$ & 85 & 90 \\
\hline Automotive & $7 \sim 15$ & 85 & 90 \\
\hline Machinery & $10 \sim 20$ & 90 & 95 \\
\hline Appliances & $4 \sim 10$ & 50 & 65 \\
\hline Steel Cans & $<1$ & 69 & 75 \\
\hline Global Ave. (weight) & - & 83 & 90 \\
\hline
\end{tabular}

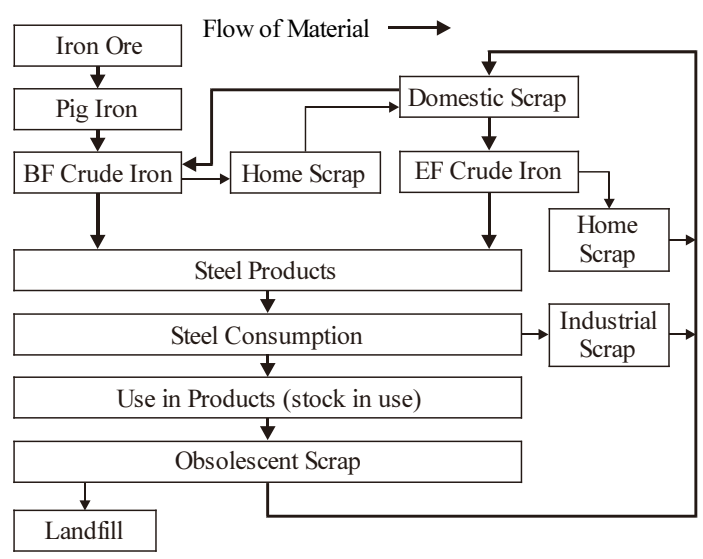

Fig. 3. Schematic diagram of life cycle of steel. 
제품의 수명이 다하여 폐기되면서 노폐 스크랩이 발생된 다. 이러한 자가발생 스크랩, 가공 스크랩, 노폐 스크랩은 전기로 제강( $\mathrm{EF}$, 일부는 전로제강)에 의해 다시 철강재로 만들어진다.

\section{3. 철강제조 프로세스의 개요}

철강산업의 3 대 기초원료에는 철광석, 철스크랩, 그리고 원료탄이 있다. 철강재료의 주원료가 되는 철광석에는 철분 함량이 높은 적철광(hematite, $\mathrm{Fe}_{2} \mathrm{O}_{3}$ )과 자철광(magnetite, $\left.\mathrm{Fe}_{3} \mathrm{O}_{4}\right)$ 이 있으며, 그 외에 갈철광(limonite), 능철광(siderite) 등이 있다. 이러한 철광석으로부터 선재, 판재 등의 제품 까지 일관하여 생산하는 공장을 고로 일관 밀(mill), 전기 로에서 주원료인 철스크랩을 용해하여 제품을 만드는 공 장을 전기로 밀, 슬래브, 블룸, 빌릿 등의 반제품을 가열. 압연하여 제품으로 만드는 공장을 압연 밀이라 한다. 철 스크랩은 전기로 제강의 주원료로 사용되지만, 전로(BOF) 에서도 잉여 열량을 이용하기 위해 일정 비율의 철스크랩 을 사용하고 있다.

Fig. 4에는 철강제조의 주류를 이루고 있는 고로 일관 철강제조 프로세스와 전기로 제강 프로세스를 같이 나타 내었다 ${ }^{12)}$. 고로(용광로)-예비처리(탈황, 탈린 등)-전로(전 기로)-2차정련(LF, RH 등)의 공정을 거쳐서 목표로 하는
성분과 온도로 제어한 용강을 연속주조(CC) 설비에서 슬 래브(slab), 블룸(bloom), 빌릿(billet) 등으로 주조한다. 이러한 주편(鑄片)을 대응하는 압연기에서 목표로 하는 형상으로 압연하여 제품으로 만든다.

\section{4. 철스크랩의 리사이클링}

\section{1. 철스크랩의 분류}

전기로 제강에서는 주원료가 철스크랩이며, 전로 제강 에서도 약 10 20\%의 철스크랩을 냉각재로 사용하고 있 다. Fig. 1 로부터 전세계 조강 생산량의 약 $43 \%(\mathrm{BOF}$ 에 서 $15 \%$ 의 철스크랩을 사용하는 것으로 가정)는 철스크 랩으로부터 제조되는 것으로 추정할 수 있다. 이러한 철스 크랩은 제강공정 자체에서 발생하는 것과 철강 수요산업 인 조선이나 자동차 제조공정의 가공과정 및 철강제품의 사용불능 상태 등에서 발생된 것을 수집과정을 통해 회수 되어 철강재 생산에 재투입되는 철강재를 모두 포함한다.

일반적인 철스크랩의 분류방법에는 크게 발생원에 따 른 분류와 용도 및 구입형태에 따른 분류 방법이 있다. 철 스크랩의 $\mathrm{KS}$ 인증기준의 심사기준과 철스크랩의 분류기 준(KS D2101, 2010. 11.)은 한국철강협회의 철스크랩 위 원회에서 발행한 '철스크랩 매뉴얼'에 자세하게 설명되어 있다 ${ }^{13)}$. 한편 철스크랩을 발생원에 따라 분류하면 국내 스

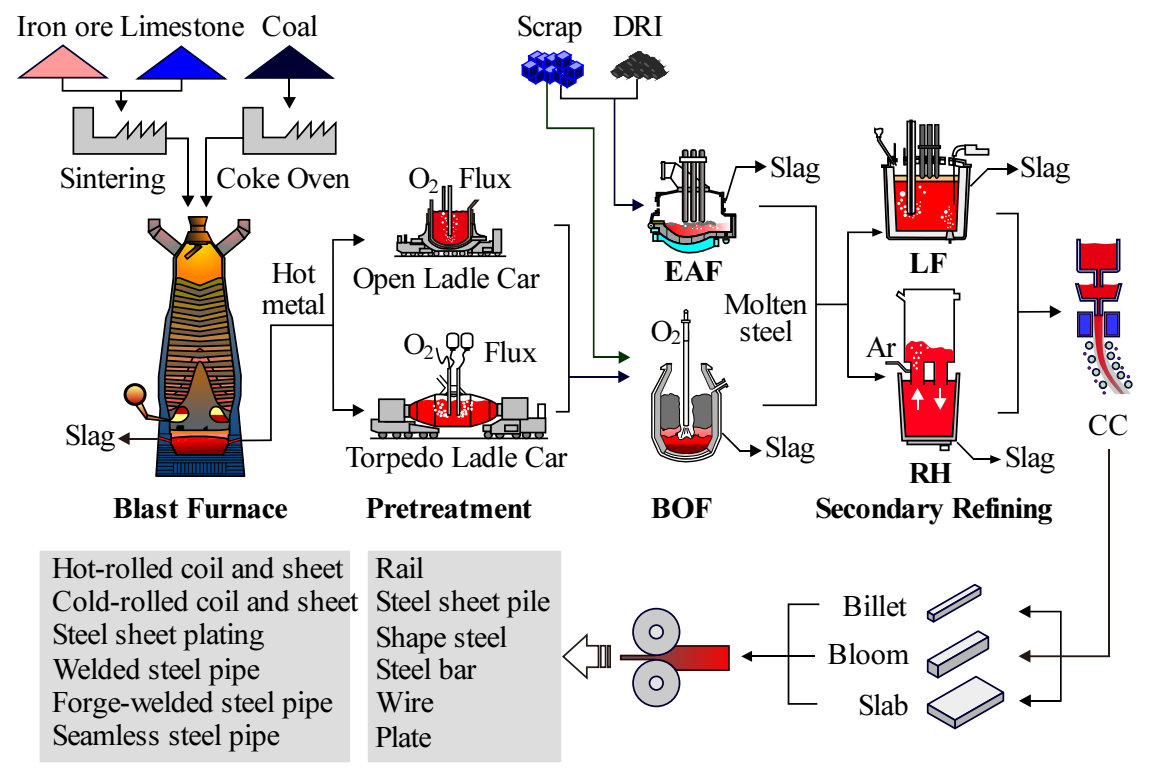

Fig. 4. Iron and steelmaking processes. 
크랩과 수입 스크랩으로 구분하고 있으며, 이러한 스크랩 의 상세내용은 다음과 같다 ${ }^{14)}$.

\subsection{1. 자가발생 스크랩(Return or home scrap)}

자가발생 스크랩은 제강공정 또는 철강재의 제조공정 에서 발생하는 것으로, 대부분 강괴, 블룸, 빌릿, 파이프, 봉강, 형강 등이다. 자가발생 스크랩은 별도의 처리나 가 공을 하지 않고 대부분 전량회수 되어 사용된다. 특히 성 분관리가 용이하여 특수합금 성분의 회수에도 유리하다.

\subsection{2. 가공산업 스크랩(Prompt industrial scrap)}

가공산업 스크랩은 철강재를 이용하여 제품을 제조하 는 과정에서 발생하는 것을 의미한다. 재사용을 위한 회 수경로 및 주기가 노폐 스크랩에 비해 짧다. 자가발생 스 크랩이나 가공산업 스크랩은 특정 강재로부터 비교적 대 량으로 발생되므로 관리가 쉽다. 특히 가공산업 스크랩은 비철부품 등을 조립하기 전에 발생하기 때문에 비철금속 이 혼입될 염려가 적어 불순물 측면에서 리사이클링이 용 이한 스크랩이다.

\subsection{3. 노폐 스크랩(Obsolescent scrap)}

노폐 스크랩은 철강제품의 내구 년 수가 다하여 폐기된 것으로, 리사이클링에 적합하도록 가공 처리되는 스크랩 이다. 대표적으로는 폐자동차나 폐가전은 물론 건축물의 해체나 기계류의 폐기 등에 따라 발생한다. 이러한 노폐 스크랩은 다양한 형상을 하고 있어서 회수 후에 크기조절, 파쇄, 부피감소 등의 가공을 하므로 스크랩 중의 성분 농 도를 파악하는 것이 곤란하다. 시중에서 구입하는 스크랩 의 대부분은 노폐 스크랩으로 사용 후 제품으로부터 발생 하며, 특히 경량 스크랩은 비철금속, 비금속으로 구성되 어 있는 부품의 함유율이 높고 철분의 함유율이 낮다. 따 라서 노폐 스크랩은 리사이클링 측면에서 문제가 되는 스 크랩이며, 발생량은 철강 축적량에 비례(철강축적량의 약 $2.5 \%)$ 한다.

한편 철스크랩을 용도에 따라 분류하면 제강용 스크랩 과 압연용 및 주물용이 있다. 제강용은 전기로 등에서의 용해과정을 거쳐서 강재로 생산되는 스크랩이며, 압연용 스크랩은 용해를 거치지 않고 가열한 후 압연하는 스크랩 을 의미한다.

\section{2. 철스크랩의 전처리}

철스크랩 중에서도 노폐 스크랩은 품위와 형상이 다양 하기 때문에 발생한 형상 그대로 제강공정에서 사용할 수 없다. 따라서 대부분은 구입 회사의 규격에 맞게 선별되 고 가공되어 납품되고 있다. 특히 폐자동차나 대형가전제 품은 일정 수준까지 분해한 후에 슈레더(shredder, 파쇄. 선별기)에서 처리한다. 파쇄한 것은 다시 프레스 가공기 에서 압축, 부피감소, 압밀화 등의 처리를 한다. 그 외에도 장대한 스크랩의 경우 절단가공을 하여 제강사에 공급하 고 있다.

\subsection{1. 슈레더(Shredder)}

슈레더는 냉연 박판 등으로 제작된 자동차나 가전제품 등 비철금속이나 비금속(플라스틱, 고무 등 금속 이외의 것)을 많이 함유하고 있는 대형 폐기물을 파쇄하여 철, 비 철, 분진 등을 자력, 중력 등으로 분리·회수하는 장치이다. Fig. 5에 폐자동차를 슈레더에서 처리하고 재료별로 선별 하는 공정의 예를 모식적으로 나타내었다. 슈레더는 본체 외에 프리 슈레더(pre-shredder, 재료를 본체에 장입하기 전에 어느 정도 잘게 파쇄하는 장치), 자력 선별기, 비철금 속 선별장치(비철금속을 금속 종류별로 분별하는 장치), 더스트 분리장치, 집진장치, 그리고 이러한 것을 연결하 는 컨베이어 등을 포함하는 상당히 대규모의 장치이다.

메인 슈레더에서는 고속으로 회전하는 원통형의 드럼 에 설치된 여러 개의 해머(날의 일종)로 재료를 주먹만 한 크기로 파쇄한다. 이보다 작고 가벼운 유기물 입자들은 공기로 이송되어 분진으로 포집된다. 그리고 파쇄된 재료

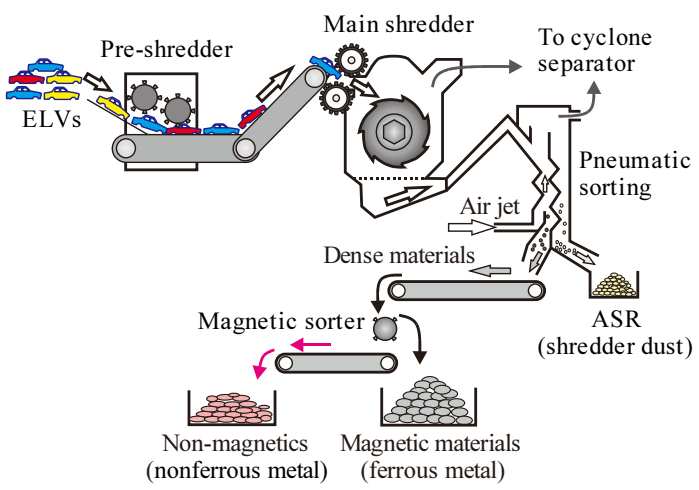

Fig. 5. Schematic illustration of a shredder and sorting of materials from ELVs. 
들은 자력선별, 체질, 중력(풍력) 등을 이용하여 선별한다. 비철금속은 다시 구리, 알루미늄 등으로 분리하여 리사이 클링하고, 비금속은 더스트로 처리된다. 초기의 개발 목 적은 페차 처리용이었으나 냉장고, 세탁기 등 폐가전품의 증가에 대응하여 철 이외에 비철금속, 비금속으로 구성되 어 있는 복합 스크랩으로부터 유가물의 회수 및 대량발생 에 따른 대량처리의 필요성과 불순물 제거에 효과적이어 서 많이 보급되었다. 그러나 설치비용이나 처리과정에서 발생하는 더스트인 ASR(Automobile Shredder Residue) 처리비용의 상승 등 문제점이 있다. 특히 스크랩 가공 과 정에서 발생하는 철 이외의 폐기물 중 재이용이 불가능한 것은 산업폐기물로 분류되기 때문에 현재로서는 매립 이 외는 별다른 방법이 없어서 환경문제는 물론이고 그 비용 은 스크랩의 원가상승 요인으로 작용할 수 있다.

한편 슈레더 더스트(ASR)는 플라스틱, 고무, 섬유, 목 재 등의 혼합물이므로 소각하여 열회수를 하기도 하며, 제련소에서 열회수와 동시에 잔존하는 금속을 추출하기 도 한다. 실제로 일본 아오모리의 세이난 상사에서는 슈 레더 더스트를 유동로(Fluidized Bed) 타입의 가스화로에 투입하여 보조연료 없이 $1,350{ }^{\circ} \mathrm{C}$ 이상의 고온에서 다이 옥신을 완전히 분해하고, 발생한 열로 증기터빈을 돌려 전력을 생산하고 있다. 이 공정에서 가스화로는 무산소 분위기이기 때문에 금속상태의 분말이 회수되고 있으며, 자력선별에 의해 처리한다. 또 생성된 슬래그는 콘크리트 골재, 블록재, 노반재 등 다양한 리사이클링 자원으로써 이용되고 있다.

\subsection{2. 절단 가공기(Sharing Machine)}

절단 가공기는 파이프나 건축자재 등 어느 정도 두께가 있으면서 길이가 긴 재료를 취급하기 편하게 일정한 길이 로 절단하는 장치이며, 현재 처리량이 가장 많은 가공법 이다. Fig. 6에 절단 가공기(a)의 모식도를 나타내었으며, 길이가 긴 스크랩을 일정한 크기로 절단하므로 철스크랩 의 균일화에 의한 제강능력 향상에 기여하고 있다. 1957년 경에는 길로틴이라 불리는 압축 절단기(프레스 셰어링)가 등장하여 프레스 및 절단과 같은 효과를 가지면서 부착물 에 의한 2 차 공해방지 효과가 있어서 현재 대부분의 절단 가공기는 이러한 압축 절단 방식을 적용하고 있다. 조작 방법은 우선 재료를 철제 상자에 장입하여 예비 압축을 한 후 눌름판으로 절단하기 쉬운 형상으로 다시 압축한 후 절
단기를 이용하여 일정한 크기로 절단한다. 그리고 기계류 와 같이 매우 큰 재료여서 크기나 두께의 한계 때문에 슈 레딩이나 절단가공이 곤란한 경우에는 아세틸렌 가스 버 너를 이용하여 수작업으로 절단한다. 그 후에 재료에 따 라서 절단 하기도 한다.

\subsection{3. 압축 가공기(Press Machine)}

압축 가공기는 Fig. 6(b)에 나타낸 바와 같이 폐 캔이나 박판의 가공 스크랩(박판을 가공하는 공정에서 발생하는 스크랩) 등과 같이 얇고 공간이 많은 형태의 철스크랩을 운반하거나 전기로 등에 장입하기에 편리한 형태로 만들 기 위해 형틀에 넣고 유압 실린더로 압축하여 상자 모양으 로 만드는 장치이다. 경우에 따라서는 자동차와 같이 대 형의 재료를 프레스 가공하기도 한다. 압축 가공한 스크 랩은 겉보기 비중이 높아져서 취급이 용이한 장점이 있으 나 불순물의 혼입이 쉽고, 실수율이 나쁘며, 전기로에서 용해에 시간이 걸리는 단점이 있다.

(a) Sharing machine

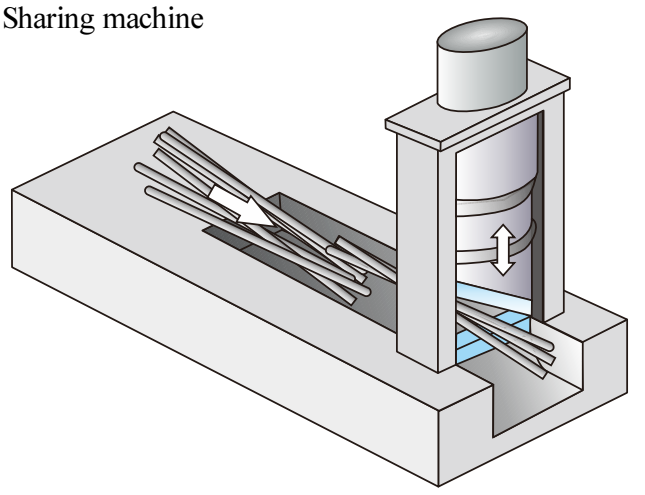

(b) Press machine

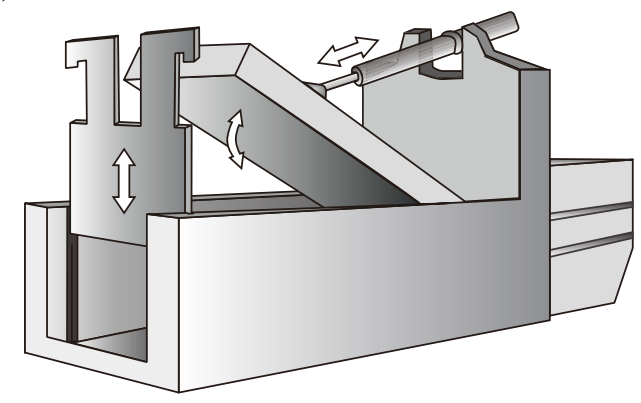

Fig. 6. Schematic illustrations of sharing machine(a) and press machine(b). 


\section{3. 철스크랩 중의 불순물}

철스크랩 중의 불순물에는 비금속과 비철금속이 있다. 비금속재료는 철강재 표면에 부착되어 있는 도료나 각종 수지재료 등의 유기물이며, 주로 프레스 스크랩 등에 혼 입되어 있다. 이러한 유기물은 제강 실수율을 저하시킬 뿐만 아니라 철스크랩을 $200 \sim 400{ }^{\circ} \mathrm{C}$ 에서 예열하는 과정 에서 기화된 후 배기 가스가 약 $100{ }^{\circ} \mathrm{C}$ 로 냉각될 때 액화 되어 백 필터(bag filter) 막힘의 원인이 되기도 한다 ${ }^{14)}$.

철스크랩 중의 비철금속 불순물은 대량 불순물, 표층 불순물, 합금계 불순물로 구분하고 있다. 대량 불순물에 는 모터류 중의 $\mathrm{Cu}$ 나 자동차 엔진 블록 등의 $\mathrm{Al}$ 이 단체로 함유되어 있는 것을 말한다. 표층 불순물은 아연도금이나 주석도금과 같이 철강의 표면에 비철금속상으로 존재하 는 것이다. 그리고 합금계로는 $\mathrm{Cu}$ 가 함유된 내후성 강이 나 스테인리스강 등에 비철금속이 합금원소로 함유되어 있는 것이다. 그러나 스테인리스강의 경우 별도로 관리되 기 때문에 혼입될 염려는 적다.

한편 철스크랩의 품질저하 원인은 다음과 같다. ${ }^{14)}$

(1) 철강제품의 고급화에 의한 특수원소 첨가강 및 특수 원소 부착강의 증가(예: 각종 고장력강, 내후성강, 스테인리스강, 특수강, 적층강판, 도금강판(아연도 금, 주석도금, 합금도금, 복합도금) 등)

(2) 최종제품의 고급화 및 고성능화에 의한 이물질 혼입 과 소형화에 의한 분리 곤란(예: 자동차, 가전제품, 사무기기 등의 전기배선, 모터, 전자 스위치류, 특수 부품(베어링, 비철부품))
(3) 성분 허용값이 엄격하지 않은 재료의 리사이클링 사 용(예: 철근 bar, 형강 등 내부 강도용 재료)

장래의 철스크랩 품질을 관리하기 위해서는 재료구성 이 과거로부터 현재까지 어떻게 변해 왔는가, 그리고 장 래에 어떠한 재료로 구성될 것인가를 예측하는 것이 필요 하다. 따라서 자동차 등 관련업계의 사용재료 동향을 파 악하는 것이 필요하다.

철강재의 품질에 악영향을 미치는 미량원소를 통틀어 tramp elements라 하며, $\mathrm{Cu}, \mathrm{Sn}, \mathrm{Cr}, \mathrm{Zn}, \mathrm{P}, \mathrm{S}, \mathrm{Ni}, \mathrm{Mo}$ 등 이 있다. 미량원소 중에서도 산소와의 친화력이 철보다 높은 $\mathrm{Al}, \mathrm{Ti}, \mathrm{Cr}$ 등은 산화정련 과정에서 산화물이 되어 슬 래그로 제거된다. 그러나 철보다 산소와의 친화력이 낮은 $\mathrm{Cu}, \mathrm{Sn}, \mathrm{Ni}$ 등은 용탕 중에 안정하게 존재하여 산화정련 으로는 제거가 불가능에 가까운 원소들이다.

Table 3에는 철강 품질에 미치는 미량원소의 영향을 나타내었다 ${ }^{15)}$. Ni과 $\mathrm{Cr}$ 은 대부분 스테인리스강에 합금원 소로 함유되어 있으며 고가의 원소이므로 스테인리스강 으로 재용융되어 큰 문제가 되지는 않는다. $\mathrm{Zn}$ 는 제강공 정(특히 전기로 제강)에서 증발하여 분진으로 포집되어 리사이클링되고 있다. 그러나 철강재료의 열간 가공성에 악영향을 미치는 $\mathrm{Cu}$ 와 $\mathrm{Sn}$ 은 산화정련으로는 제거할 수 없기 때문에 희석에 의해 대처하고 있다. 특히 $\mathrm{Cu}$ 와 $\mathrm{Sn}$ 의 순환축적에 의한 철스크랩의 품질열화가 우려되므로 주 의하여야한다.

Fig. 7에는 대형 양질의 스크랩(a)과 형강(b), 봉강(c) 스크랩에 대해 $\mathrm{Cu}$ 와 $\mathrm{Sn}$ 의 농축 예상값을 추정한 예를 나

Table 3. Adverse effects of tramp elements on the quality of steel products in recycling scraps

\begin{tabular}{|c|c|}
\hline Element & Adverse effect on quality of steel \\
\hline $\mathrm{Cu}$ & - Adversely affects hot workability at content of about $0.2 \%$ \\
\hline $\mathrm{Sn}$ & $\begin{array}{l}\text { - Adversely affects hot workability at content of about } 0.04 \% \\
\text { - Adversely affects cold workability and temper brittleness at content of about } 0.2 \%\end{array}$ \\
\hline $\mathrm{Ni}$ & - Increase hardness and objectional for sheet product \\
\hline $\mathrm{Cr}$ & $\begin{array}{l}\text { - Increase hardness and objectional for sheet product } \\
\text { - Adversely affects cold workability }\end{array}$ \\
\hline $\mathrm{Zn}$ & - Forms white smoke during iron casting \\
\hline $\mathrm{Pb}$ & - Adversely affects hot workability at content of $0.001 \%$ \\
\hline As & $\begin{array}{l}\text { - Adversely affects hot workability at content of } 0.03 \% \\
\text { - Adversely affects cold workability and temper brittleness at content of about } 0.02 \%\end{array}$ \\
\hline $\mathrm{Bi}$ & - Adversely affects hot workability at content of $0.005 \mathrm{wt} \%$ \\
\hline
\end{tabular}



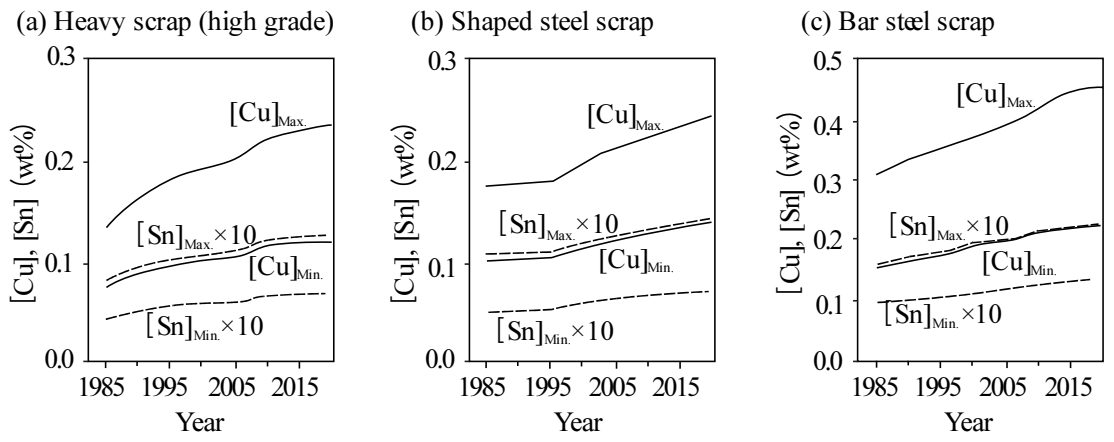

Fig. 7. Enrichment of $\mathrm{Cu}$ and $\mathrm{Sn}$ in various obsolete scraps.

Table 4. Variations of acceptable level of $\mathrm{Cu}$ and $\mathrm{Sn}$ contents of steel with the steel grade (wt\%)

\begin{tabular}{|c|c|c|}
\hline Steel grade & $\mathrm{Cu}$ & $\mathrm{Sn}$ \\
\hline Deep draw quality plate & $\leq 0.06$ & $\leq 0.010$ \\
\hline Hot or cold rolled sheet & $\leq 0.10$ & $\leq 0.020$ \\
\hline Shape steel & $\leq 0.30$ & $\leq 0.025$ \\
\hline Steel Bar & $\leq 0.40$ & $\leq 0.060$ \\
\hline
\end{tabular}

타내었다 ${ }^{14)}$. 대형 양질의 스크랩인 경우에도 2020 년 경에 는 $\mathrm{Cu}$ 의 경우 최대 $0.24 \mathrm{wt} \%$ 까지 농축될 것으로 예상되 며, 봉강의 경우 최대 $0.45 \mathrm{wt} \%$ 가 농축되는 것으로 예상 되고 있다. 따라서 이러한 스크랩은 서서히 사용하기 힘 든 철원이 될 것으로 예상되므로 스크랩 중 불순물 원소 제거기술의 개발이 시급한 실정이다.

Table 4에는 대표적인 철강제품에서 $\mathrm{Cu}, \mathrm{Sn}$ 농도의 허 용 수준을 나타내었다. 강종에 따라 차이는 있으며, $\mathrm{Cu}$ 나 $\mathrm{Sn}$ 의 함유율이 높은 스크랩의 경우 심가공용(deep drawing) 으로 리사이클링하는 것이 곤란한 것을 알 수 있다 ${ }^{16}$.

\section{4. 철 스크랩 중 불순물의 제거}

철스크랩 중의 불순물을 제거하는 방법에는 고체상태 에서 제거하는 물리적인 제거법과 금속의 물성 및 열역학 적 특성을 이용하여 고온에서 처리하는 화학적인 제거법 이 있다. 대표적인 물리적 처리법에는 수작업에 의한 비 철금속류 및 비금속류의 제거와 스크랩 가공 처리기에 의 한 선별, 그리고 저온파쇄법이 있다. 그리고 건식 화학적 제거법에는 철과 구리의 융점차를 이용한 탈동법, 용융금 속욕 이용법, 용융 맷트(matte)법 등이 있으며 탈주석 기 술로는 가열 황화법 등이 있다.
전기모터, 배전반, 전선 등에는 $\mathrm{Cu}$ 가 함유되어 있으며, 이러한 것들이 함유되어 있는 EoL(end of life)품은 Fig. 5 에 나타낸 슈레더 등에서 처리되는 경우가 많다. 슈레더 처리에서는 자력선별, 풍력선별과 수선별을 조합하면 동 이나 $\mathrm{Al}$ 등의 비철금속, 플라스틱이나 타이어 등의 비금 속을 높은 효율로 분리할 수 있다 ${ }^{17)}$. 폐자동차의 슈레더 처리 후 엄격한 수선별을 하면, 구리는 $0.015 \%$ 까지 낮아 지며, 생산성 및 경제성을 무시한 반복처리 시험에서도 도달 가능한 한계가 $0.08 \%$ 인 것과 비교하면 탁월한 선별 능력이 있는 것을 알 수 있다. 최근에는 스크랩의 색도인 식, X-선 분석기 등을 이용하여 비철금속을 선별하기도 한다. 그러나 철과 동이 복잡하게 결합되어 있는 모터 core 등과 같은 재료는 현재의 물리적 선별기술로는 충분 한 분리가 불가능한 실정이다.

철강제품과 비철금속이 결합되어 있는 스크랩은 저온 파쇄를 이용할 수 있다. 철은 $-50 \sim-130{ }^{\circ} \mathrm{C}$ 로 냉각하면 취 화되지만, $\mathrm{Cu}$ 및 $\mathrm{Cu}$ 합금은 액체질소의 비등점인 $-196{ }^{\circ} \mathrm{C}$ 까지 냉각하여도 취화되지 않는다. 실제로 이용되고 있는 온도영역은 금속계의 경우 $-100{ }^{\circ} \mathrm{C}$, 비금속계는 $-30{ }^{\circ} \mathrm{C}$ 이하이다. 따라서 비철금속과 결합되어 있는 철스크랩을 취화온도 이하로 낮추어 파쇄하면 한성분 만 분리할 수 있 으며, 자력선별과 조합하면 혼입된 $\mathrm{Cu}$ 의 약 $95 \%$ 이상을 제거할 수 있고, 동시에 분리된 비철금속의 품위도 높아 진다. 다만 냉매의 원단가가 높은 문제점이 있다.

철스크랩 중의 $\mathrm{Cu}$ 를 융점차이를 이용하여 선택적으로 용해시켜 제거하는 방법이 제안되어 있다. 철스크랩의 온도 를 높여서 구리의 융점인 $1,083{ }^{\circ} \mathrm{C}$ 와 철의 융점인 $1,535^{\circ} \mathrm{C}$ 의 중간 온도까지 가열하면 철은 용융되지 않고 구리만 액 체로 되어 선택적으로 제거할 수 있다. 그러나 실제로는 
용융 $\mathrm{Cu}$ 의 표면장력 때문에 고체철의 표면으로부터 분리 하기가 쉽지는 않다. 용융 분위기 중의 산소분압을 높여 서 철 표면을 magnetite 안정영역으로 하면 용융 $\mathrm{Cu}$ 의 고 체철에 대한 젖음성이 현저하게 낮아져서 철 표면으로부터 $\mathrm{Cu}$ 를 효과적으로 제거할 수 있는 것으로 알려져 있다 ${ }^{18,19)}$.

Iwase 등은 용융 알루미늄 중에서 $\mathrm{Cu}$ 의 활동도가 매우 낮다는 원리를 이용하여 고체 철스크랩 중의 $\mathrm{Cu}$ 를 용융 알루미늄욕으로 선택 용해시킬 수 있는 것으로 보고하였 다 ${ }^{20,21)}$. 또 Katayama 등은 $600 ~ 750^{\circ} \mathrm{C}$ 범위에서 $\mathrm{Mg}$ 계 합 금을 이용하면 철스크랩 중의 $\mathrm{Cu}$ 를 제거할 수 있는 것으 로 보고하였다 ${ }^{22)}$. 이러한 연구는 $\mathrm{Cu}$ 의 회수 측면에서는 경제성을 확보할 수 있을 것으로 기대되고 있다.

Fruehan 등은 $\mathrm{Cu}$ 와 $\mathrm{Fe}$ 의 $\mathrm{S}$ 친화력 차이를 이용하여 $\mathrm{Cu}$ 를 아래 식과 같이 맷트로 만들어 제거하고자 하였다 ${ }^{23)}$.

$$
2 \mathrm{Cu}(\mathrm{s})+\mathrm{FeS}(\text { matte })=\mathrm{Cu}_{2} \mathrm{~S}(\text { matte })+\mathrm{Fe}(\mathrm{s})
$$

그러나 이 반응은 반응물과 생성물이 모두 고체이기 때 문에 반응이 느리므로, $\mathrm{FeS}-\mathrm{Na}_{2} \mathrm{~S}$ matte를 이용하면 약 700 ${ }^{\circ} \mathrm{C}$ 이하에서도 고-액 반응을 진행시킬 수 있다. 19 25\% $\mathrm{Na}_{2} \mathrm{~S}-\mathrm{FeS}$ matte와 $\mathrm{Cu} 1 \%$ 의 모의 철 스크랩을 800 $1,000{ }^{\circ} \mathrm{C}$ 범위에서 반응시켜 온도에 따라서 $75 \sim 90 \%$ 의 $\mathrm{Cu}$ 를 제거한 것으로 보고하였다.

한편 $\mathrm{Sn}$ 은 도금 등 부착성 불순물이 주 발생원이다. $\mathrm{Sn}$ 도금 강판의 표면을 산화시키면 $\mathrm{Sn}$ 이 산화막과 함께 박리 되거나 약산화 분위기에서 고온으로 하면 주석이 증발 제 거되는 것으로 보고되어 있다. 또 고체 상태의 철스크랩 표면에 존재하는 $\mathrm{Sn}$ 을 일정 온도에서 황화시켜 주석층을 박리제거하는 방법도 보고되어 있다 ${ }^{24)}$.

철스크랩 중의 미량원소를 습식 화학적 방법으로 제거 하는 프로세스도 알려져 있다. 특히 습식 화학적인 방법 은 상온처리이므로 열에너지 소요량이 적으며, 다양한 분 리 프로세스가 확립되어 있고, 완전한 폐쇄 프로세스이므 로 환경대책이 용이한 장점이 있다. 특히 선택성이 있으 므로 순수물질을 회수할 수 있는 장점도 있다. 그러나 대 량처리에는 적절하지 못하며, 프로세스가 복잡하여 처리 비용이 높고, 폐수처리가 필요한 문제점도 있다. 따라서 습식 화학적인 방법은 소량이면서 다양한 불순물을 함유 하는 원료를 처리하기에 적합하다.

상기한 방법들은 철스크랩을 용융하기 전에 미리 제거
하는 방법이지만, 용융 상태에서 제거하는 여러 가지 방 법들도 보고되어 있다. 특히 철스크랩 중 미량원소의 순 환방지를 위해서는 용탕으로부터 제거하여야 한다. 산화 정련에서 $\mathrm{Cu}$ 와 $\mathrm{Sn}$ 의 제거는 곤란하지만, 증발에 의해서 는 제거할 수 있다. 증기압이 높은 $\mathrm{Zn}, \mathrm{Pb}$ 등은 상압하에 서도 쉽게 증발할 수 있으며, 평형 증기압이 철과 유사한 $\mathrm{Cu}$ 와 $\mathrm{Sn}$ 은 감압하에서 증발시켜 제거할 수 있다 ${ }^{25)}$. 또 $\mathrm{Sn}$ 은 $\mathrm{SnS}$ 로 황화시켜 증발시킬 수도 있다. Sasaki 등은 용선 중에 암모니아 가스를 취입하여 $\mathrm{Sn}$ 을 제거하고자 하였으 며 ${ }^{26)}$, Matsui 등은 용철 중 $\mathrm{Cu}$ 를 황화물 플럭스를 이용하 여 $\mathrm{Cu}$ 황화물로 만들어 제거하고자 하였다 ${ }^{27)}$. 그러나 이 러한 방법들은 반응속도나 경제성 등이 확보되지 못하여 아직 실용화 단계에 이르지는 못하고 있다.

\section{5. 철스크랩의 용융}

철스크랩은 Fig. 4에 나타낸 바와 같이 고로법의 전로 공정에서도 사용되지만, 전기로 제강에서 주원료로 사용 되고 있다. 특히 전기로 제강법은 철스크랩이나 환원철과 같은 냉철원을 원료로 사용하고, 전기에너지를 이용하여 용해정련하는 방법으로, 순산소 전로(BOF) 다음으로 중 요한 제강법이며, 철스크랩의 리사이클링 관점에서 가장 대표적인 공정이다.

Fig. 8에는 철스크랩을 원료로 사용하여 철근이나 소형 $\mathrm{H}$ 형강 등 건설·구조용강을 생산하는 전기로(EAF, electric arc furnace) 조업의 예를 모식적으로 나타내었다. 주원료 인 철스크랩 등을 장입하여 용해 및 정련을 한 후에 출강 한다. 스테인리스강이나 합금강 등의 특수강, 고급선재나 봉강을 생산하는 경우에는 필요에 따라 LF(ladle furnace), VOD(Vacuum Oxygen Decarburization), AOD(Argon Oxygen Decarburization), RH(Ruhrstahl-Hausen) 등에 서 2차정련을 하기도 한다.

이러한 전기로 조업의 용해기에서는 장입된 고체상태의

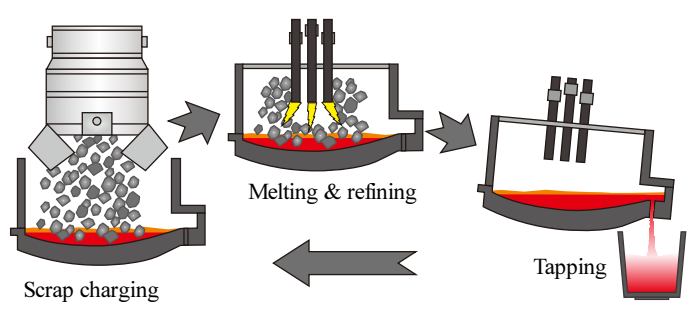

Fig. 8. Operation of EAF manufacturing reinforcing bars. 
철스크랩이 용융되기 시작되며, 이때부터 휘발성 물질 $(\mathrm{Zn}$ 등)이 제거되기 시작한다. 정련공정은 산화기, 환원기로 구 분하며, 산화기에는 산소취입에 의한 산화정련으로 아래식 과 같이 불순을 제거하고, 목표 탄소량으로 조정한다.

$$
\begin{aligned}
& {[\mathrm{C}]+[\mathrm{O}]=\mathrm{CO}(\mathrm{g})} \\
& {[\mathrm{Si}]+2[\mathrm{O}]=\left(\mathrm{SiO}_{2}\right)} \\
& {[\mathrm{Mn}]+[\mathrm{O}]=(\mathrm{MnO})} \\
& 2[\mathrm{P}]+3(\mathrm{CaO})+5[\mathrm{O}]=\left(3 \mathrm{CaO} \cdot \mathrm{P}_{2} \mathrm{O}_{5}\right)
\end{aligned}
$$

또 탈탄 비등에 의해 용강 중 수소나 질소의 탈가스 등 이 일어나며, 고염기도, 고산화성 슬래그에 의해 탈린을 촉진한다. 특히 전기로 조업에서는 탈탄에 의해 발생하는 $\mathrm{CO}$ 가스의 방출과정에서 용철의 비산과 $\mathrm{Zn}$ 과 같이 비등 점이 낮은 성분의 휘발이 활발하게 일어난다.

환원기에서는 탈산, 탈황, 합금성분의 조정 및 출강온 도의 조정 등이 이루어지며, 탈황반응은 식 (6)과 같다.

$$
[\mathrm{S}]+(\mathrm{CaO})=(\mathrm{CaS})+[\mathrm{O}]
$$

현재는 노외정련(2차정련)의 보급에 의해 환원기를 단 축하거나, 완전히 생략하는 경우가 많다.

Fig. 9에는 일반 전기로의 에너지 수지를 나타내었다. 그림에서와 같이 전기로 조업은 다량의 전기에너지를 소

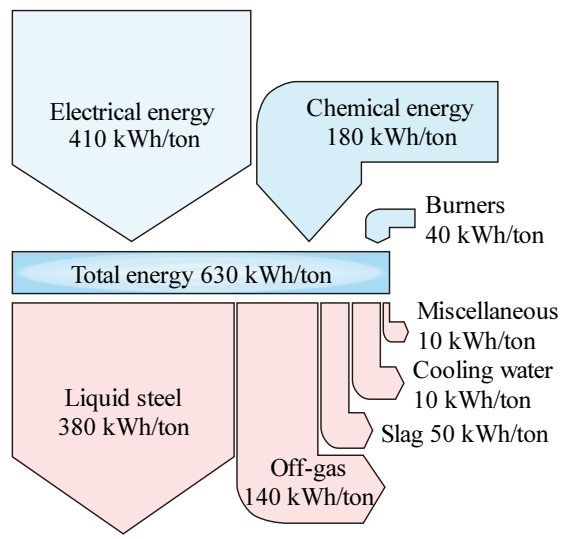

Fig. 9. Energy balance of conventional EAF.
비하므로 열효율을 높이기 위한 새로운 형태의 전기로들 이 개발되어 조업 중에 있다. 특히 철 스크랩을 투입하기 전에 예열하여 용해에 필요한 전기 에너지를 절약하고 있 다. 따라서 최근의 전기로는 스크랩을 수직 샤프트형이나 수평형 장입설비에서 예열할 수 있도록 개발되어 있다. 스크랩 예열에 의해 약 $50 \sim 70 \mathrm{kWh} / \mathrm{t}$ 의 전력을 절약할 수 있다. 스크랩의 예열은 다음식과 같이 전기로 내에서 발 생한 $\mathrm{CO}$ 가스의 2차 연소에서 발생하는 열을 이용하기도 한다.

$$
\begin{aligned}
& 2 \mathrm{CO}(\mathrm{g})+\mathrm{O}_{2}(\mathrm{~g})=\mathrm{CO}_{2}(\mathrm{~g}), \\
& \Delta G^{0}=-565,160+172.03 T(\mathrm{~J})
\end{aligned}
$$

Fig. 10에는 수직형인 Finger shaft로의 모식도와 조업 예를 나타내었다 ${ }^{28)}$. 전극은 직류형과 교류형이 있으며, 약 23기 정도가 가동 중에 있다. 이러한 수직형의 경우 우수 한 생산성과 전기에너지 절약 및 실수율 향상 등에 효과가 있고, 특히 샤프트에 장입되어 있는 스크랩이 더스트를 포집하여 더스트 발생량이 적은 장점이 있다. 그러나 스 크랩 등에 부착되어 있거나 혼입된 플라스틱류의 연소에 의해 다이옥신 등이 발생하므로 샤프트 후단에서 2차 연소 와 함께 배기가스의 급냉이 필요하다. $\mathrm{NKK}$ 의 ECOARC 로에서는 이러한 처리를 하고 있다. 또 finger가 손상될 염 려가 있으므로 중량 스크랩은 장입할 수 없는 문제점도 가

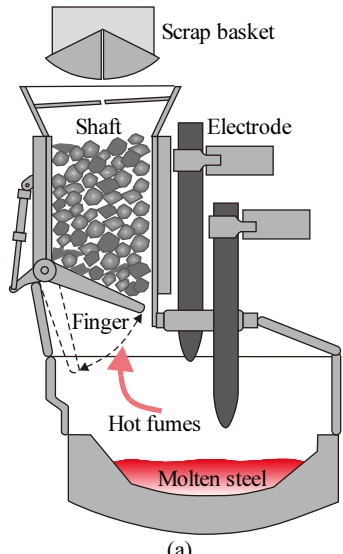

(a)

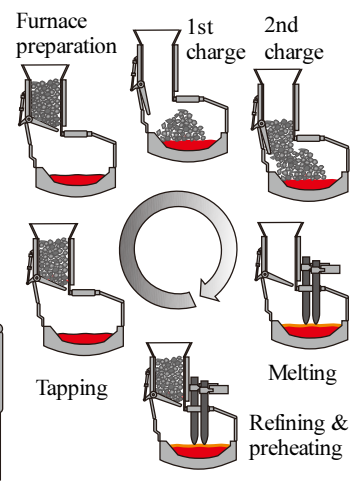

(b)
Fig. 10. Electric furnace with off-gas energy recovery by preheating scrap in a shaft. (a) scheme for Finger shaft furnace, (b) Operating cycle for a shaft furnace charging two scrap baskets. 


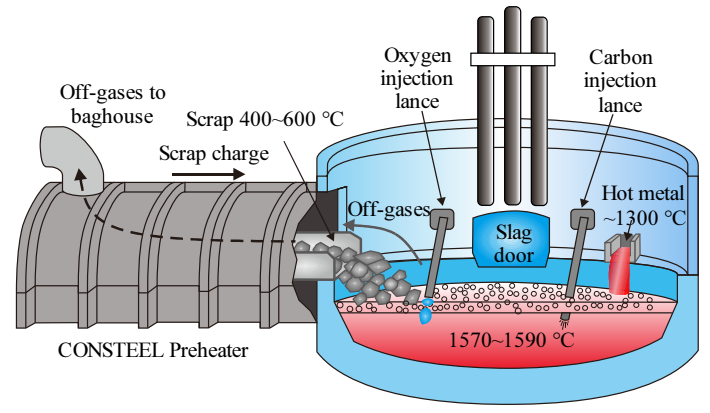

Fig. 11. Continuous scrap charging and off-gas energy recovery with Consteel EAF.

지고 있다.

Fig. 11에는 수평형의 연속 스크랩 예열식 전기로인 Consteel법(Techint)의 개념도를 나타내었다. Consteel법 은 일관 제철소 전체의 생산능력 유연성을 확보하기 위해 종래의 설비를 유효하게 활용하면서 일관 제철소의 일부 또는 전체를 개조하여 시간당 300 톤 이상의 생산성을 가 지는 고품질의 미니밀로서 가동되고 있다. 특히 Consteel 법은 $70 \%$ 의 철스크랩과 약 $30 \%$ 의 용선을 사용할 수 있 어서 제강 코스트가 BF-BOF에 비하여 낮으며, 투자비 회 수도 1 년 이내 인 것으로 알려져 있다. 현재 제강 능력은 60 300 ton/h 정도이며, 전세계에 약 30 기 이상이 가동 중에 있다. 특히 미국과 중국에 많이 설치되어 있으며29), 우리나라의 동부제철에서도 2009년부터 160 ton 용량의 Consteel 2기를 가동하고 있다.

그 외에도 SMS Demag는 측벽으로부터 스크랩을 수평 연속 장입하는 CHS Scrap charger(Continuous Horizontal Sidewall scrap charger)를 제안하였다. 또 전로 겸용형 전 기로에는 CONARC(SMS Demag), ARCON(Concast) 등이 개발되어 있다.

\section{5. 제철·제강공정의 분진 처리}

\section{1. 제철소 발생 분진}

철강 생산 프로세스에서 철광석의 소결설비, 고로(BF, blast furnace), 전로(BOF, basic oxygen furnace) 등에서 발생하는 가스 중에 함유된 더스트(dust)나 압연시에 발 생하는 밀스케일(mill scale)에는 산화철, 탄소, 기타 성분 들이 들어 있다. 일관 제철소에서의 더스트, 밀스케일, 슬 러지를 포함하는 제철분진의 발생량은 조강 생산량의 약
Table 5. Chemical compositions of dust generated in steelmaking plants (wt\%)

\begin{tabular}{|c|c|c|c|c|c|c|}
\hline Type & T.Fe & T.Ni & T.Cr & C & Zn & $\mathrm{Na}+\mathrm{K}$ \\
\hline C-steel & $45 \sim 55$ & - & & $6 \sim 15$ & $0.3 \sim 3$ & $01 \sim 0.6$ \\
\hline STS & $20 \sim 30$ & $2 \sim 4$ & $8 \sim 12$ & - & & $3 \sim 5$ \\
\hline
\end{tabular}

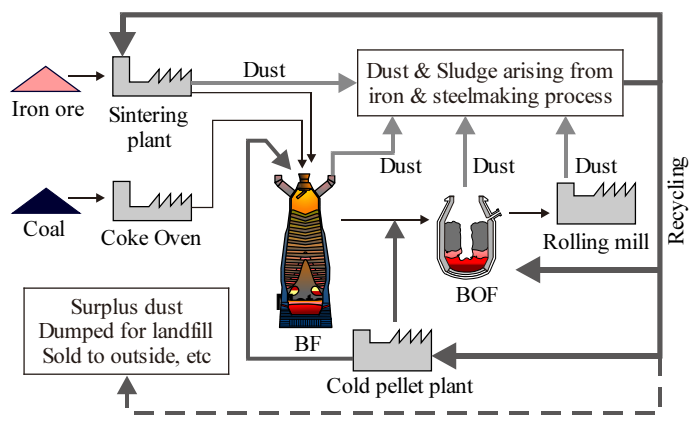

Fig. 12. Dust generation and flow from iron and steelmaking plants.

$10 \%$ 정도이다. Table 5 에는 탄소강 및 STS 제조공정에 서 발생하는 더스트의 성분 예를 나타내었으며, Fig. 12에 는 제철소에서 발생하는 더스트의 흐름도를 재구성하여 모식적으로 나타내었다 ${ }^{30)}$.

이러한 더스트의 대부분은 소결이나 콜드 펠릿(cold pellet) 등의 원료로 재이용하여 왔으며, 일부는 매립하거 나 시멘트의 가철제 등으로 판매하여 왔다. 한편 더스트 중에는 소량의 $\mathrm{Zn}$ 가 함유되어 있으며, 고로에 장입되는 전체 아연량이 증가하면 고로 내에서 아연의 부착물이 생 성되어 고로조업에 지장을 초래한다. 따라서 아연 함유량 이 높은 더스트(20 30\%) 등은 폐기하여 왔다.

\section{2. 제철소 발생 분진의 리사이클링 기술}

제철분진을 자원화하기 위해서는 아연을 분리하여야 하며, 기본적으로는 고온 환원 증발법(건식법)과 습식침 출-전기분해법(습식법)이 있다. 습식법의 경우 철분은 수 산화철로서 회수되므로 대부분은 건식법에 의해 처리하 고 있다.

제철분진의 건식처리법은 산화철과 산화아연 등을 함 유하는 분말을 $1,000{ }^{\circ} \mathrm{C}$ 이상의 온도에서 환원하는 방법 으로 반응식은 다음과 같다.

$$
\mathrm{FeO}_{t}+t \mathrm{C}=\mathrm{Fe}(\mathrm{s})+t \mathrm{CO}(\mathrm{g}) \quad(t: 0.95 \sim 1.5)
$$




$$
\mathrm{ZnO}(\mathrm{PbO})+\mathrm{C}=\mathrm{Zn}(\mathrm{Pb})(\mathrm{g})+\mathrm{CO}(\mathrm{g})
$$

환원된 아연이나 납은 증기가 되어 계외로 배출되므로 산화철로부터 얻어진 금속철과 분리할 수 있다. 이러한 건식처리법에는 회전노상형인 RHF법, 환원전기로를 사 용하는 ESRF법, 샤프트로법, 로터리 킬른법 등이 있으나, 본 고에서는 제철소에서 가동되고 있는 RHF법과 ESRF 법에 대해 설명한다. 나머지 방법들은 제강분진의 처리기 술에서 상세하게 설명하고 있다 ${ }^{31)}$.

\subsubsection{RHF법}

RHF법의 노체 설비는 INMETCO식과 FASTMET식 ${ }^{32)}$ 등이 있다. RHF는 도너츠 형상의 회전로를 중심으로하는 고온환원 프로세스이며, 원료준비 및 조립공정, RHF에서
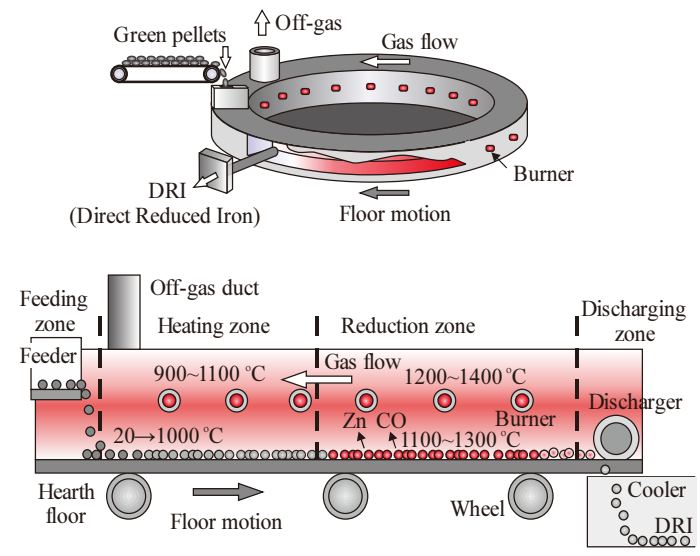

Fig. 13. Schematic diagram of RHF and hearth.

Table 6. Specifications of dust recycling plants in Japan Steel

\begin{tabular}{|c|c|c|}
\hline & No. 1 DRP & No. 2 DRP \\
\hline Agglomerate & $\begin{array}{c}\text { Pellet } \\
\text { (disc pelletizer) }\end{array}$ & $\begin{array}{c}\text { Wet processing } \\
\text { (compactor) }\end{array}$ \\
\hline Hearth diameter & $20 \mathrm{~m}$ (at hearth center) \\
\hline Hearth area & $230 \mathrm{~m}^{2}$ & $230 \mathrm{~m}^{2}$ \\
\hline Processing capacity & $22 \mathrm{t} / \mathrm{h}$ & $17 \mathrm{t} / \mathrm{h}$ \\
\hline (green pellet base (dry)) & $15,000 \mathrm{t} / \mathrm{month}$ & $10,000 \mathrm{t} / \mathrm{month}$ \\
\hline Green pellet diameter & $5 \sim 20 \mathrm{~mm}$ & $5 \sim 30 \mathrm{~mm}$ \\
\hline Processing temp. & $1,250 \sim 1,300{ }^{\circ} \mathrm{C}$ & $1,250 \sim 1,300{ }^{\circ} \mathrm{C}$ \\
\hline Retain time & $10 \sim 20 \mathrm{~min}$ & $15 \sim 30 \mathrm{~min}$ \\
\hline Off-gas system & Boiler, air heater, bag house \\
\hline
\end{tabular}

의 환원공정, 배가스 처리공정 등으로 구성되어 있다 ${ }^{31)}$. Fig. 13에는 RHF의 모식도와 노상(rotary hearth)의 구조 를 나타내었다. 그리고 Table 6에는 일본제철에서 가동중 인 RHF 설비의 주요 사양을 나타내었다 ${ }^{30)}$.

제강분진 등을 비롯한 제철소에서 발생하는 더스트 등 을 탄소질 환원제와 함께 혼합하여 펠릿이나 브리켓트로 만들어 회전로 중에 균일한 두께로 장입한다. 원료 펠릿은 노상의 진행에 따라 우선 가열 존에서 $1,000{ }^{\circ} \mathrm{C}$ 이상까지 가열된다. 환원존은 $1,200 ~ 1,400{ }^{\circ} \mathrm{C}$ 이며, 펠릿은 $1,100{ }^{\circ} \mathrm{C}$ 이상의 반응온도에 도달하여 함유탄소에 의해 산화철과 산화아연의 환원반응이 진행한다. 즉, 식 (8)의 환원반응 에 의해 환원철이 생성되며, 식 (9)의 반응에 의해 $\mathrm{Zn}$ 증 기가 발생한다. 따라서 아연은 기화되어 펠릿으로부터 분 리되는 탈 $\mathrm{Zn}$ 반응이 진행한다. $\mathrm{Zn}$ 증기는 배가스 계통에 서 산화되어 조산화 아연으로 백필터에서 회수된다. 또 여분의 $\mathrm{CO}$ 가스는 2 차연소에 의해 열에너지로 활용된다. 연소가스 및 반응가스는 노상의 진행방향과 반대방향으 로 흐르며, 환원된 펠릿은 배출장치를 통해 노외로 배출 된다.

노내에서 환원된 환원철(DRI)은 고온인 상태로 반출 되어 전로, 전기로, 토피도 레이들 등에서 이용하거나, 냉 각하여 고로에서 사용하기도 한다. 또 RHF에서 배출된 DRI를 직접 용해로에서 용해(FASTMELT process)시켜 용선으로 만들기도 한다 ${ }^{32)}$.

포스코의 포항 및 광양제철소의 각각 년산 20 만 톤 규 모의 RHF가 가동 중에 있으며, 그 외에도 일본, 중국, 대 만 등에 수 기가 가동 중에 있다. RHF는 환원철을 제조할 수 있을 뿐만 아니라 전기로 더스트 중의 아연회수 장치로 도 활용되고 있다.

\subsubsection{ESRF법}

ESRF(Electric Smelting Reduction Furnace)법은 2010 년부터 대만에서 가동 중에 있는 제강 더스트 처리용의 용 융환원로이며, Fig. 14에 개념도를 나타내었다 ${ }^{33,34)}$. 고상 의 환원철이 생성되는 RHF법과 달리, ESRF에서는 용융 선철이 제조된다.

RHF법과는 달리 전기 에너지를 열원으로 사용하므로, 발생하는 가스량이 적어 원료의 비산이 적다. 또 용융환 원이므로 철분도 완전히 환원되어 용선으로 회수되므로 전기로의 철원으로 사용하고 있다. 그리고 $1,250{ }^{\circ} \mathrm{C}$ 이상 


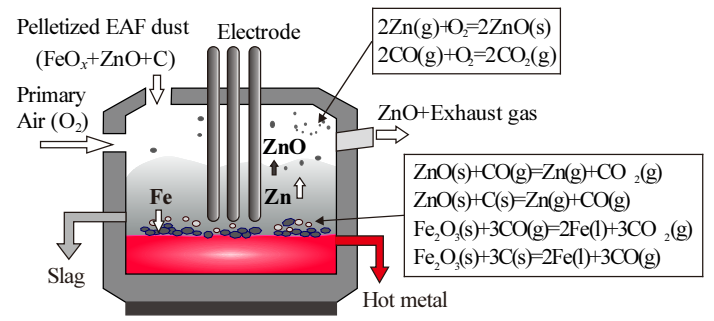

Fig. 14. Basic concept of ESRF (Electric Smelting Reduction Furnace).

의 고온에서 가동되므로 더스트 중의 다이옥신은 완전히 열분해 되는 것으로 알려져 있다. 특히 설비가 간단하여 전기로 공장 내에 설치하여 제강분진을 처리하고, 배출되 는 용선은 곧바로 전기로에서 철원으로 사용할 수 있는 장 점이 있다. 현재 대만의 KCRC(Katec Creative Resources Corporation)에서 년간 4 만 톤의 제강분진과 5 천 톤의 의 료 폐기물을 처리하여 년간 12,500 톤의 선철과 15,500 톤의 조산화 아연을 생산하고 있는 것으로 알려져 있다.

\subsection{3. 밀스켈일의 처리}

강재의 제조과정이나 사용과정에서 주성분이 산화철 $\left(\mathrm{FeO}, \mathrm{Fe}_{3} \mathrm{O}_{4}, \mathrm{Fe}_{2} \mathrm{O}_{3}\right)$ 인 밀스케일이 발생한다. 이러한 밀 스케일은 다량의 철분 $(\mathrm{Fe})$ 을 함유하고 있으므로 주로 철 강제련공정에서 철 $(\mathrm{Fe})$ 공급원으로 사용하고 있다. 밀스 켈일은 상기한 RHF나 ESRF에서 처리하기도 하지만, 단 순히 브리켓팅만 하여 고로의 철광석 대체재로 투입하거 나, 제강공정인 $\mathrm{BOF}$ 에 잉여 열량을 조절하기 위한 냉각 제(coolant)로 투입하고 있다. 필요에 따라서는 반응성을 향상시키기 위하여 환원제(페로실리콘 등)와 혼합하여 브 리켓팅을 하기도 한다.

\section{6. 종 합}

본 논문에서는 철스크랩을 리사이클링하기 위해 필요 한 철강제조 프로세스와 철스크랩을 주원료로 사용하는 전기로 제강법, 철스크랩의 전처리와 불순물 원소, 그리 고 철강공정에서 발생하는 제철분진의 처리기술에 대해 고찰하였다. 철은 구조용 금속으로는 $\mathrm{Al}$ 다음으로 지구상 에 가장 많이 존재하는 매우 친숙한 금속으로, 철을 리사 이클링하면 철광석으로부터 환원하여 철강재를 얻는 것
에 비하여 $\mathrm{CO}_{2}$ 발생량은 약 $42 \%$ 수준이며, 에너지는 약 $60 \%$ 를 절약할 수 있다. 2018년 기준 전세계 조강 생산량 은 18 억 톤을 초과하였으며, 중국의 조강 생산량은 약 9.3 억 톤으로 전세계 조강 생산량의 반을 차지하고 있다. 철 강재의 수명을 고려하면 향후 중국에서 대량의 철스크랩 이 발생할 것으로 예상된다. 2017년 기준 우리나라의 조 강 생산량은 약 7,100 만 톤이며, 이 중에서 철스크랩을 이 용한 조강 생산량은 약 2,800 만 정도로 추정되고 있다.

철스크랩을 리사이클링하는 경우 형상에 따라 슈레더, 절단기, 압축기 등의 다양한 전처리를 하고 있지만, 가장 문제가 되는 것은 $\mathrm{Cu}, \mathrm{Sn}$ 등의 미량원소 제거이다. 철강재 는 산화정련으로 만들어지고 있으므로, 산소와의 친화력 이 철보다 현저하게 낮은 $\mathrm{Cu}, \mathrm{Sn}$ 등은 현재로서는 수작업 및 가공처리기에 의한 제거가 가장 효율적이며 경제적인 방법이다. 따라서 철스크랩의 리사이클링률을 높이기 위 해서는 미량원소의 효율적인 제거에 대해 많은 연구가 필 요할 것이다. 그리고 철스크랩은 전기로 제강의 주원료로 사용되고 있으며, 원가절감을 위해 스크랩을 예열하는 장 치를 부가한 에너지 절약형 전기로로 바뀌어 가고 있다. 한편 철강 제조공정에서는 다량의 제철분진이 발생하고 있으며, 이러한 제철분진은 제철소 내에서 다양한 방법으 로 리사이클링하여 철분과 아연 등을 회수하고 있다. 그 러나 다양한 성분의 제철분진을 처리하기 위한 새로운 리 사이클링 기술에 대한 연구도 필요할 것으로 생각된다.

\section{References}

1. Posco, 1997 : Steel Story, p.10, Posco, Seoul, Korea.

2. Sohn, Ho-Sang, 2019 : Engineering of resource recycling, p.1, KNU Press, Daegu, Korea.

3. Sue Grimes, John Donaldson, and Gabriel Cebrian Gomez, 2008 : Report on the environmental benefits of recycling, p.4, Bureau of International Recycling (BIR), Brussels, Belgium.

4. Norgate, T. E. and Rankin, W. J., 2002 : The role of metals in sustainable development, Green Processing 2002, (The AusIMM), Cairns, May 2002, pp.49-55.

5. World Steel Association, 2019 : Monthly crude steel production, WSA, Brussels, Belgium.

6. Ernst Worrell and Markus A. Reuter, 2014 : Handbook of recycling: State-of-the-art for practitioners, analysts, and scientists, p.4, Elsevier Inc., Oxford, UK.

7. World Steel Association, 2019 : World crude steel pro- 
duction-summary, World Steel Association, Brussels, Belgium.

8. World Steel Association, 2012 : Sustainable steel at the core of a green economy, p.6, WSA, Brussels, Belgium.

9. World Steel Association, 2016 : Steel-The permanent material in the circular economy. p.5, WSA, Brussels, Belgium.

10. World Steel Association, 2012 : Sustainable steel at the core of a green economy, p.14, WSA, Brussels, Belgium.

11. Matsuno, Y., 2007 : Recycling of steel, J. of MMIJ, 123(12), pp.845-849.

12. Sohn, Ho-Sang, 2019 : Engineering of resources recycling, p.263, KNU Press, Daegu, Korea.

13. Steel Scrap Committee, 2013 : Manual of ferrous scrap, pp.18-20, Korea Iron \& Steel Association.

14. Sohn, Ho-Sang and Jung, W.G., 1997 : Removal of tramp element in ferrous scrap, Bulletin of the Korean Inst. of Met. \& Mat., 10(1), pp.70-81.

15. Yamaguchi, K., 2011 : Removal of tramp element in molten iron by two liquid phase separation, p.8, Doctor Thesis of Osaka University.

16. Katayama, H. and Mizukami, Y., 1996 : Recycling of ferrous scrap, Materia Japan, 35(12), pp.1283-1289.

17. Sohn, Ho-Sang, 2019 : Engineering of resources recycling, p.263, KNU Press, Daegu, Korea.

18. Miyazaki, S., Hara, S., and Ogino, K., 1992 : Effect of oxygen partial pressure on the wettability of solid iron with molten copper, CAMP-ISIJ, 5(1), p.13.

19. Mukai, K, Yamakawa S., Matubara T., et al., 1994 : Effect of oxygen partial pressure on copper removal ratio from solid steel, CAMP-ISIJ, 7(1), p.5.

20. Iwase, M. and Tokinori, K., 1991 : A feasibility study for the removal of copper from solid ferrous scrap, Steel Research, 62(6), pp.235-239.

21. Iwase, M., Tokinori, K., and Oshita, H., 1992 : Effect of temperature upon copper removal from solid ferrous scrap, CAMP-ISIJ, 5(1), p.14.

22. H. G. Katayama, T. Momono, M. Doe, and H. Saitoh, 1994 : Dissolution rate of stationary solid copper cylinder into molten $\mathrm{Al}-\mathrm{Cu}$ and $\mathrm{Mg}-\mathrm{Cu}$ alloys, ISIJ International, 34(2), pp.171-176.

23. Jimbo, I., Sulsky, M.S., and Fruehan, R.J., 1988: The Refining of Copper from Ferrous Scrap, Iron and Steelmaker, 15(8), pp.20-23.

24. Tokumitsu, N., 1990 : Stripping of tin from tin plate (Removal of tin from scrap by utilizing $\mathrm{SnS}$ formation reaction-I), CAMP-ISIJ, 3(4), p.1183.
25. Chen, X., Ito, N., Nakashima, K., et al., 1995 : Evaporation rate of copper in high carbon iron melt under reduced pressure, Tetsu-to-Hagane, 81(10), pp.959-964.

26. Sasaki, N., Uchida Y., Mikim Y., et al., 2016 : Fundamental study of $\mathrm{Sn}$ removal from hot metal by $\mathrm{NH}_{3}$ gas blowing, Tetsu-to-Hagane, 102(1), pp.17-23.

27. Matsui, A., Uchida Y., and Takahashi Y., 2016 : Removal of copper from molten iron to promote utilization of steel scrap, JFE Report, 38, pp.58-62.

28. Madias, Jorge, 2014 : Electric furnace steelmaking, p.292, Treatise on Process Metallurgy, Volume 3, Industrial Processes, Ed. by Seshadri Seetharaman, Elsevier Ltd.

29. Memoli, Francesco and Ferri, Mauro Bianchi, 2008 : 2007 - A record year for consteel, Millennium Steel, pp.83-88.

30. Oda, H., Ibaraki, T., and Abe, Y., 2006 : Dust recycling system by the rotary hearth furnace, NSC Kibou, 384, pp.134-139.

31. Sohn, Ho-sang, 2018 : Status of pyrometallurgical treatment technology of EAF dust, J. of Korean Inst. of Resources Recycling, 27(2), pp.68-76.

32. Harada, T., Tanaka, Hi., and Sugitatsu, H., 2001 : Verification of the fastmet process for steel mill waste treatment, Kobe Steel Engineering Reports, 51(2), pp.23-26.

33. M. Nakayama, 2011 : Treatment process of EAF dust by reduction smelting, Industrial Machinery, 2, pp.33-37

34. Chen, Wei-Sheng, Chou, Wei-Shan, and Tsai, Min-Shing, 2011 : Status of EAF dust management in Taiwan, J. of Korean Inst. of Resources Recycling, 20(1), pp.3-13.

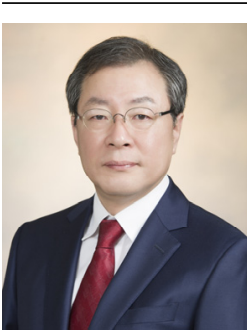

\section{손호 상}

- 1983년 경북대학교 금속공학과 공학사

- 1985년 경북대학교 대학원 금속공학과 공학석사

- 1993년 Kyoto Univ. 야금학과 공학박사

- 1985 1988년 현대자동차 기술연구소

- 1993 1994년 (주)영풍 석포제련소 기술 연구소

- 1994 2001년 포스코 기술연구소

- 2001년 현재 경북대학교 금속신소재공 학과 교수

- 2013 2015년 경북대학교 공과대학 학장

- 2017 2018년 한국자원리싸이클링학회 회장 